\title{
Raising Healthy Children: Family Fitness ${ }^{1}$
}

\author{
Lisa D. Chan, Ashley Hamm, Shari Bresin, and Karla P. Shelnutt ${ }^{2}$
}

\section{The Obesity Epidemic}

The Centers for Disease Control and Prevention (CDC) report that $18.4 \%$ and $20.6 \%$ of children in the United States ages 6-11 and 12-19, respectively, have obesity (CDC, 2019). This number is rising and is a concern for many parents. Childhood obesity can lead to serious future health problems, including diabetes, high cholesterol, high blood pressure, heart disease, and cancer. One of the main reasons many children gain weight is a lack of physical activity. Television, video games, and computer games (referred to as "screen time") take up too much of our children's daily lives, leaving little time for active play (Mitchell, Rodriguez, Schmitz, \& Audrain-McGovern, 2013).

\section{Enriching Your Life with Physical Activity}

Does being active really make a difference? Yes! Physical activity can provide many health benefits for you and your family. It's something everyone should do every day. Being physically active can improve your overall health, help the whole family manage their weight, and provide a great way to spend time with your family (CDC, 2011).

\section{Benefits for Children}

Regular physical activity can help children be healthier now and in the future. Daily activity can help children maintain a healthy body weight and reduce their risk of developing

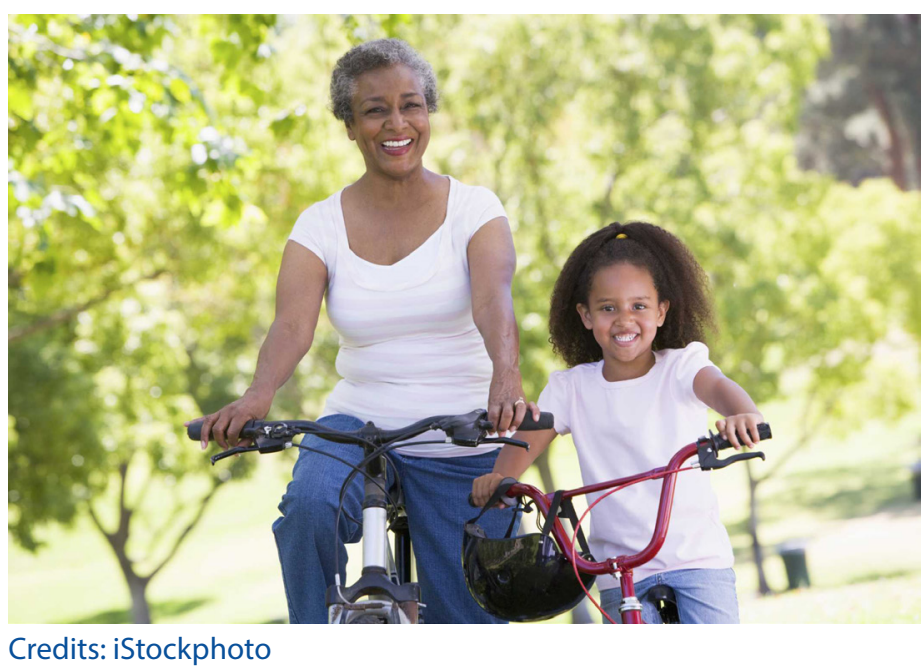

diseases associated with obesity. Children 3 to 5 years of age should be physically active throughout the day through active play and structured activities. School-age youth 6 to 17 years should be physically active one hour a day each day, combining aerobic exercises (such as riding bikes or swimming) with muscle-strengthening activities (such as climbing trees or playground equipment) and bonestrengthening exercises to promote bone growth (including jumping rope or basketball). Many aerobic activities can also count as bone-strengthening or muscle-strengthening (Physical Activity Guidelines for Americans, 2018).

1. This document is FCS8892, one of a series of the Department of Family, Youth and Community Sciences, UF/IFAS Extension. Original publication date December 2009. Revised November 2020. Visit the EDIS website at https://edis.ifas.ufl.edu for the currently supported version of this publication.

2. Lisa D. Chan, former dietetic intern, Master of Science-Dietetic Internship Program, Food Science and Human Nutrition Department; Ashley Hamm, former dietetic intern, Master of Science-Dietetic Internship Program, Food Science and Human Nutrition Department; Shari Bresin, Extension agent, family and consumer sciences, UF/IFAS Extension Pasco County; and Karla P. Shelnutt, PhD, RD, associate professor, Department of Family, Youth and Community Sciences; UF/IFAS Extension, Gainesville, FL 32611.

The Institute of Food and Agricultural Sciences (IFAS) is an Equal Opportunity Institution authorized to provide research, educational information and other services

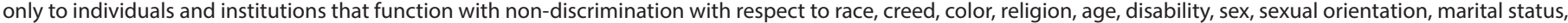

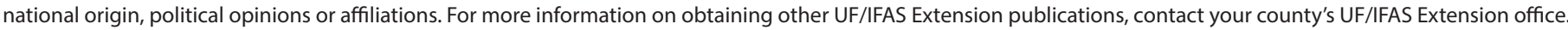
U.S. Department of Agriculture, UF/IFAS Extension Service, University of Florida, IFAS, Florida A \& M University Cooperative Extension Program, and Boards of County Commissioners Cooperating. Nick T. Place, dean for UF/IFAS Extension. 
Children who are physically active have more energy, better attitudes, and stronger muscles and bones than less active children (CDC, 2011). Activity also sends more blood to the brain, giving it oxygen and nutrients vital for brain function, which can help children in school. Being involved in physical activity also helps promote positive self-esteem and self-image in young children. The better they get at an activity, the better they will feel (CDC, 2013b).

\section{Benefits for Adults}

Physical activity is valuable for adults as well as children. Adults who exercise decrease their risk for developing diseases associated with aging such as dementia, type 2 diabetes, and osteoporosis (Bowen, 2012; CDC, 2011). Aim for 150 minutes of moderate-intensity aerobic activity per week, or 75 minutes of vigorous-intensity aerobic activity per week. Use the talk test to determine your intensity level: at a moderate level, you can talk, but can't sing; at a vigorous level, you have to pause every few words to catch your breath. It is also recommended that adults do strength training exercises at least twice per week.

Besides lowering disease risk, exercise gives parents more energy. Having more energy means more motivation to play with your children! Plus, with your newfound energy, you can spend some time fixing healthy meals at home.

Physical activity has other benefits for adults. It can increase strength, balance, and flexibility, all of which impact overall health and quality of life. Exercise can also help busy parents cope with stress in a healthy way (U.S. Department of Health and Human Services, 2006). Additional benefits include improved sleep, reduced anxiety and depression, better success with weight loss or weight maintenance, improved cognition, and overall lowered risk of all-cause mortality (Physical Activity Guidelines, 2018).

\section{Making Family Time Healthy and Fun}

There are many activities you can do as a family to increase everyone's activity level and have fun! Try some of these games with your family or ask your kids for their ideas.

- Play tag. This game is an old favorite people of every age can enjoy!

- Take your kids to the park and chase them around the playground. The laughter will surely give your core a workout!

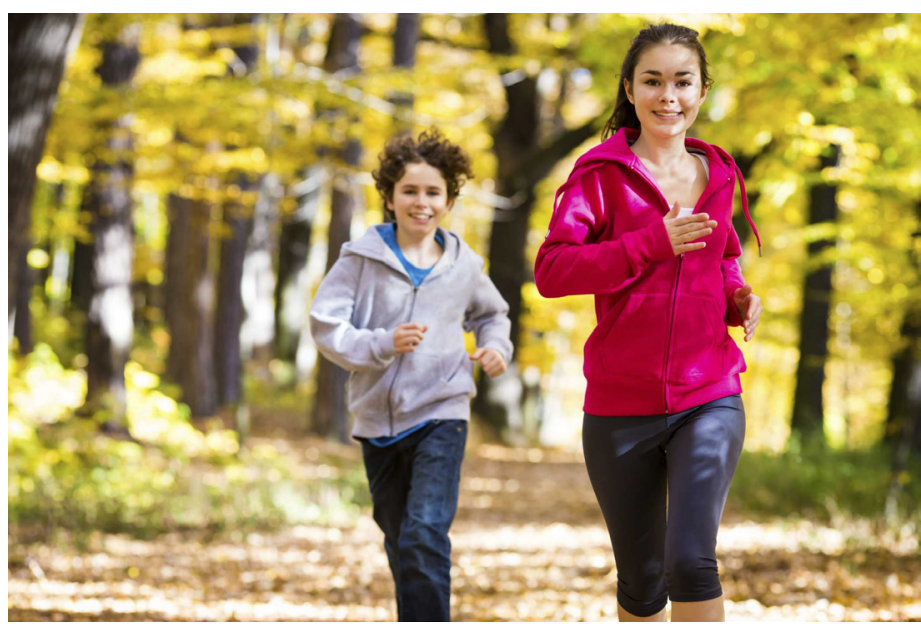

Credits: iStockphoto

- Play music your family enjoys and dance around the house. You can make a game out of it by pausing the music and freezing, or playing musical chairs!

- Workout videos for kids can be fun and can get you and your child moving!

- Head out on a family bike ride. Kids can also rollerblade or skateboard!

- Join a gym or recreation center that provides exercise classes for parents and kids together.

- Head to the local park and bring a variety of athletic gear-basketballs, soccer balls, and a bat and baseball, just to name a few.

- If your children are still very young, put them in a baby carrier or stroller and go for a walk.

- If your children are part of a sports team, make time to practice a little bit with them every day.

\section{Adding Activity Everywhere}

Even when you don't have time for planned physical activity, there are ways you can work physical activity into your day.

- Park farther away from the front of the grocery store so you can take a little walk.

- Take the stairs instead of the elevator. Your kids can pretend they are hiking up a big mountain!

- When the kids are watching a TV show, have them get up during commercial breaks and do jumping jacks to get their heart rates up. 
- When you are getting your children ready for school in the morning, turn on some music and dance around the living room.

- Set up a special section in your garden for your child. When you are out on Saturday morning working in the yard, your child can join you instead of watching cartoons.

\section{Being a Positive Role Model}

As a parent, you should model positive behavior. TV, peers, and magazines affect children, so you need to set good examples for your children at home. You can have a big impact in their lives and on the choices they make.

Daily activity is important to your child's health. Showing your children that physical activity is something you value may make it important to them. If you make an effort to exercise every day, they will notice. If you watch TV for hours each day, your kids will take note. Be a good role model. Encourage your children to establish habits that will get them moving and keep them active. A physically active childhood will set them up for a healthy adulthood.

\section{More than Just Fitness}

Physical activity will improve the health of your family, but it has other benefits as well. Doing physical activity as a family allows you to spend quality time with your children while doing something that benefits you both. Family fitness time offers health benefits and strong family ties. Enjoy spending this valuable time with your family!

\section{Recommended Websites}

USDA’s MyPlate: http://www.choosemyplate.gov

This website explains USDA's MyPlate food guide and ways to apply its concepts to your everyday life.

USDA's Kids' Corner: https://www.nutrition.gov/topics/ nutrition-age/children/kids-corner

This website provides a list of resources that children can use to learn about nutrition and physical activity.

\section{References}

Bowen, N. E. (2012). A Prospective Examination of the Relationship between Physical Activity and Dementia Risk in Later Life. American Journal of Health Promotion, 26(6), 333-40. https://doi.org/10.4278/ajhp.110311-QUAN-115
Centers for Disease Control and Prevention (CDC). (2011). Physical Activity and Health: The Benefits of Physical Activity. Retrieved from http://www.cdc.gov/physicalactivity/ everyone/health/

CDC. (2013a). Child Obesity Facts: Health Effects of Child Obesity. Retrieved from http://www.cdc.gov/healthyyouth/ obesity/facts.htm

CDC. (2013b). Physical Activity and the Health of Young People. Retrieved from http://www.cdc.gov/healthyyouth/ physicalactivity/facts.htm

CDC. (2019). Childhood Obesity Facts: Prevalence of Childhood Obesity in the United States. Retrieved from https://www.cdc.gov/obesity/data/childhood. html\#: :text=Prevalence\%20of\%20Childhood\%20 Obesity\%20in\%20the\%20United\%20States\&text=For\%20 children\%20and\%20adolescents\%20aged,to\%20 19\%2Dyear\%2Dolds

Mitchell, J. A., Rodriguez, D., Schmitz, K. H., \& AudrainMcGovern, J. (2013). Greater Screen Time Is Associated with Adolescent Obesity: A Longitudinal Study of the BMI Distribution from Ages 14 to 18. Obesity Silver String, 21(3), 572-5. doi: 10.1002/oby.20157.

Physical Activity Guidelines for Americans, $2^{\text {nd }}$ Edition. (2018). Retrieved from https://health.gov/sites/default/ files/2019-09/Physical_Activity_Guidelines_2nd_edition. pdf

U.S. Department of Health and Human Services. (2006). Your Guide to Physical Activity and Your Heart. Retrieved from http://www.nhlbi.nih.gov/health/public/heart/obesity/ phy_active.pdf 